\title{
Short-term Runoff Forecasting based on Hydrological Factors at Nanchang Section of Ganjiang River, China
}

\author{
Bojun Liu ${ }^{1,3, a}$, Xiaohui Lei ${ }^{2}$, Siyu Cai ${ }^{2}$, Shaoming Peng ${ }^{3}$, and Dawei Zhang ${ }^{2}$ \\ ${ }^{1}$ Yellow River Engineering Consulting Co., Ltd Postdoctoral Programme, Zhengzhou 450003, Henan, China \\ ${ }^{2}$ China Institute of Water Resources and Hydropower Research, Beijing 100038, China \\ ${ }^{3}$ Yellow River Engineering Consulting Co., Ltd, Zhengzhou 450003, Henan, China
}

\begin{abstract}
With the change of global climate and underlying surface characteristics, and increasing human activities, hydro-meteorological factors such as precipitation, evaporation, and runoff. Etc., are directly affected, therefore the assumption of stationarity may no longer exist. In a changing environment, the conventional runoff forecasting methods become invalid, which brings challenges to accurate hydrometeorological forecast. A hydrological model based on the changing environment was employed to forecast the runoff at Nanchang Section of Ganjiang River in this paper, and the rationality and validity of the built model were verified. The results shows that the built hydrological model has high accuracy in the short-term runoff forecasting, and better forecasting effect has been obtained after the parameters calibration and the real-time correction of the predicted runoffs, which can provide the strong support for the scientific water resources operation decision and also provide the boundary conditions of water level and water quality for the hydrodynamic and water-quality simulation at the Nanchang Section of the Ganjiang River.
\end{abstract}

\section{Introduction}

Water, as the basic natural resource and a strategic economic resource, is a controlling factor for ecological environment and also an indispensable support for the development of economic society. More people with less water, uneven spatial and temporal distribution of water resources, uneven spatial and temporal distribution, and out of proportion with overall planning of social and economic development, which are the serious conditions needing to be faced with for a long time in China. Thus, the contradiction between water supply and demand is the dominating restriction on sustainable development $t^{[1]}$. Short-term runoff forecasting, as an important part of water resources operation, can not only provide the inflow information for reservoir operation on rivers, but also provide the necessary inflow boundary for the hydrodynamic and water quality model built on river or lake, so as to realize the real-time operation of reservoirs and emergency water resources operation under some sudden events ${ }^{[2]}$. The detailed information supports from short-time runoff forecasting is shown in Fig. 1.

In addition, the scientific and rationality of water resources operation in rivers can be ensued by the improvement of short-time runoff forecasting accuracy. It can be found that the uncertainty of rainfall is the main factor affecting runoff forecast in rivers, and the forecasting runoff has a greater impact on reservoir operation, that is, forecasting runoff information as one of the most important input data is directly related to the calculation of objective function, which thus can affects the decision making of reservoir operation ${ }^{[3-4]}$. Some studies suggest that in the actual operation of reservoirs, the runoff situation in the future can be reflected by the forecasting information compared to the hydrological statistical data, and runoff forecasting information used in models can effectively improve the comprehensive benefit of reservoir operation, also, the reliability of reservoir operation decision can be improved ${ }^{[5-6]}$. Moreover, when forecasting runoff information is used as the boundary condition of hydrodynamic and water quality model, its accuracy directly affects the quality of the simulated results of flow velocity, water level, and pollutant concentration in rivers ${ }^{[7]}$.

With the insight in the hydrological cycle process, hydrologists began to use the system theory to study the hydrological cycle in basin, and thus the concept of hydrological model is proposed. Generally, the conceptual hydrological model with physical significance and the systematic theoretical hydrological model similar to "black box" are included in hydrological model. The conceptual hydrological model as the most widely used model in study, and according to the discrete degree of basin space, can be divided into the lumped hydrological model and the distributed hydrological model. Stared from 1960, various conceptual hydrological models have been proposed successively by researchers, such as the Stanford model, Sacramento watershed hydrological model, Tank model, SWMM model, NAM model, HBV model, Xinanjiang rainfall-runoff model with the three components, Northern Shaanxi model and Dahuofang model ${ }^{[8-14]}$. Then, the conceptual hydrological model is further improved by the division of several interconnected

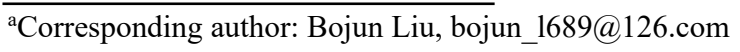


computing units in the watershed, such as the TOPMODEL model, IHDM model, SWAT model, VIC model, Vflo model, HEC-GRO model and WET-SPA model, and these models, based on the decentralized treatment and output, make the physical mechanism of basin hydrology more clear so as to reflect the hydrological differences more accurately and simulate the change process of regional hydrological cycle ${ }^{[15-18]}$.

Although Jiangxi province is located in the area with abundant water, the spatial and temporal distribution of water resources is completely uneven; inflow and water use are not synchronized, and the problems of resourceful water shortage, engineering water shortage and water shortage induced by deteriorating water quality still exist. With the rapid development of economy and society, the problem of water resource is becoming more and more serious, and currently, the decision-making ability of water resources operation in Jiangxi province cannot meet the urgent need of water resources management. Nanchang city is the capital of Jiangxi province and needs to be focused on ensuring its water resources allocation process. How to build the short-term runoff forecasting model to provide the effective forecasting information for the water resources operation at the Nanchang section of Ganjiang River, especially in the dry season, how to ensure the accuracy and effectiveness of the forecasting runoffs is an important basis for improving the capacity of water quantity allocation in river section and emergency water resources operation in case of sudden water pollution or drought events, which deserves further study. Thus, a shot-term runoff forecasting model considering river hydrological factors is built to forecast the runoff at the Nanchang section of Ganjiang River; then, the rationality of the built model is investigated and the accuracy of the forecasting runoff is analysed to obtain the effective runoff forecasting information that could provide the strongly auxiliary support for the actual water resource operation at the Nanchang section of Ganjiang River.

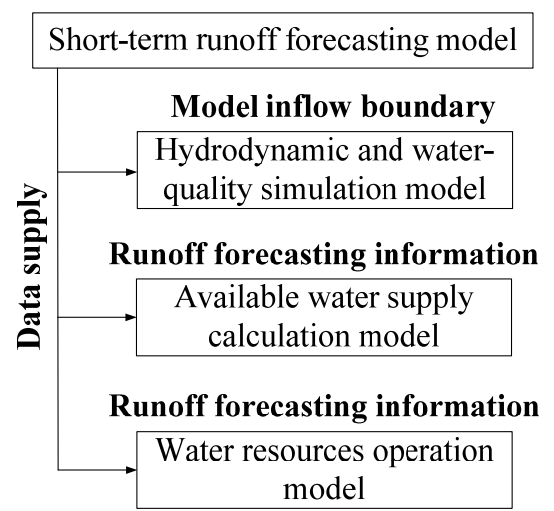

Figure 1. Model data supply from short-term runoff forecasting information

\section{Study area}

Ganjiang River is the largest river in Jiangxi province, also is the largest river flowing in toe Poyang Lake and one of the eight tributaries of the Yangtze River. Ganjiang River originates from Shicheng County and its length of the main river channel is $828 \mathrm{~km}$; the catchment area is $82809 \mathrm{~km}^{2}$ (excluding river rump) and accounts for $50 \%$ of the province's total area. The study area is the river section from the hydrological station at Zhangshu hydrological station to the hydrological station at Waizhou. Waizhou station is located in $115^{\circ} 50^{\prime} \mathrm{E}$, $28^{\circ} 38^{\prime} \mathrm{N}$, and its control basin area is $80948 \mathrm{~km}^{2}$, which is the most important hydrological monitoring station at the downstream of Ganjiang River. According to the analysis of the hydrological data at the Waizhou station, it can be found that the runoff annual distribution and the distribution of the runoff in a year are both uneven and seasonal. The monthly average flow in the dry season is smallest, with runoff accounting for $3 \%$ of total runoff in the whole year, while the monthly average flow in the flood season (April, May and June) is largest, accounting for $52.4 \%$ of total runoff in the whole year. The annual average flow of Ganjiang River is $2110 \mathrm{~m}^{3} / \mathrm{s}$ and the minimum is $172 \mathrm{~m}^{3} / \mathrm{s}$; the maximum monthly average flow is $9400 \mathrm{~m}^{3} / \mathrm{s}$ and the minimum is $254 \mathrm{~m}^{3} / \mathrm{s}$. The annually highest water level is $23.60 \mathrm{~m}$ (based on the elevation of Yellow Sea) and the lowest is $14.41 \mathrm{~m}$; and the monthly maximum water level is $20.64 \mathrm{~m}$. In addition, the measured maximum flow velocity at the Waizhou station is $20400 \mathrm{~m}^{3} / \mathrm{s}$ (June 20, 1982) and the minimum is $172 \mathrm{~m}^{3} / \mathrm{s}$ (November 3,1963 ).

Nanchang city has a subtropical humid monsoon climate with four distinct seasons. Summer of Nanchang is hot and winter is cold, with the abundant sunshine and a long frost-free period. The annual average temperature is within $\left[17^{\circ} \mathrm{C}, 17.7^{\circ} \mathrm{C}\right]$; the extremely maximum temperature is $40.9^{\circ} \mathrm{C}$ and the extremely minimum temperature is $15.2^{\circ} \mathrm{C}$. The annual average rainfall is $1589.1 \mathrm{~mm}$; the day number of precipitation is $147 \sim 157$ $\mathrm{d}$; the annual day number of rainstorm is $5.6 \mathrm{~d}$, and the annual average relative humidity is $78.5 \%$. Annual average sunshine time is $1723 \sim 1820 \mathrm{~h}$; the sunshine rate is $40 \%$ and the annual average wind speed is $2.3 \mathrm{~m} / \mathrm{s}$; the annual frost free period is $251 \sim 272 \mathrm{~d}$. Moreover, the annual average precipitation of Nanchang City is $117.64 \times 10^{8} \mathrm{~m}^{3}$, in which, the surface water resources, groundwater resources and annual average total water resources is $61.53 \times 10^{8} \mathrm{~m}^{3}, 14.65 \times 10^{8} \mathrm{~m}^{3}$ and $65.98 \times 10^{8}$ $\mathrm{m}^{3}$, respectively.

\section{Short - term runoff forecasting modelling}

\subsection{Method and Data}

In this study, a hydrological model is considered to build in the basin between the Xiajiang reservoir at Ganjiang River, Jiangkou reservoir at Yuanhe River and Waizhou station. The selected basin has the following characteristics: (1) the basin is open, and Xiajiang reservoir and Jiangkou reservoir are the entrance points of the basin; (2) the basin with the abundant rainfall is in the region of saturation excess runoff. Thus, EasyDHM model is employed to simulate the runoff at the Nanchang section of Ganjiang River ${ }^{[19-20]}$. EasyDHM model adopts the model interface of MapWindow to 
complete the hydrological simulation and parameter identification process, which can be convenient and simple to operate. The Xinanjiang water yield, Masingen convergent, LH-OAT method and SCE-UA algorithm is selected as the water yield mode, confluence mode, sensitivity analysis method and parameter calibration method of EasyDHM model ${ }^{[21-26]}$.

The original DEM data is obtained from HYGRO1k of the United States geological survey (USGS). However, there are many inconsistencies between the simulated river network directly extracted from original DEM and the actual river network, for example, the larger elevation of some DEM grids in the plain area of mountain basin leads to the formation of false depression at its upstream basin. Thus, in order to improve the accuracy of the model simulation, the original DEM needs to be revised referring to the actual river network. The original and revised DEM data is shown in Fig. 2, respectively.

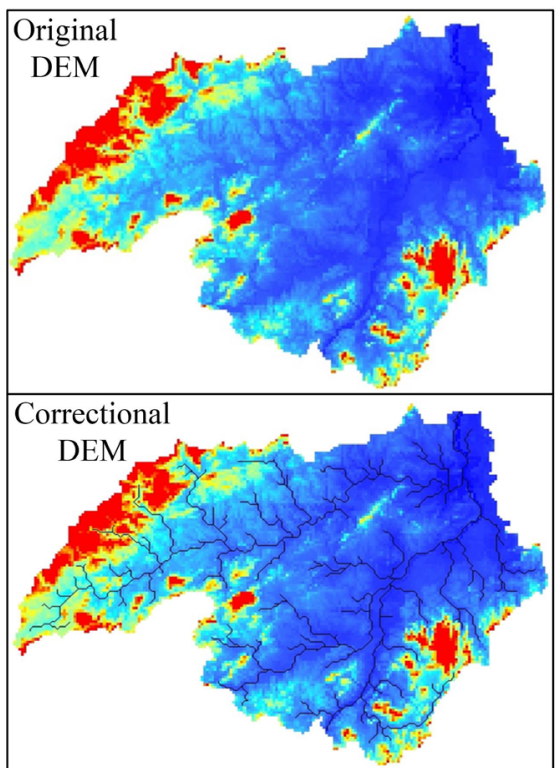

Figure 2. Original and revised DEM data image

The depression detention, flow direction generation, volume calculation of runoff confluence and rivers extraction are carried out based on the revised DEM data. While, the Xiajiang reservoir and Jiangkou reservoir are selected as the inlets; Waizhou station is selected as the outlet; the threshold of river area is set to be $50 \mathrm{~km}^{2}$, and thus, the river system at Nanchang section of Ganjiang River can be obtained (seen in Fig. 3).

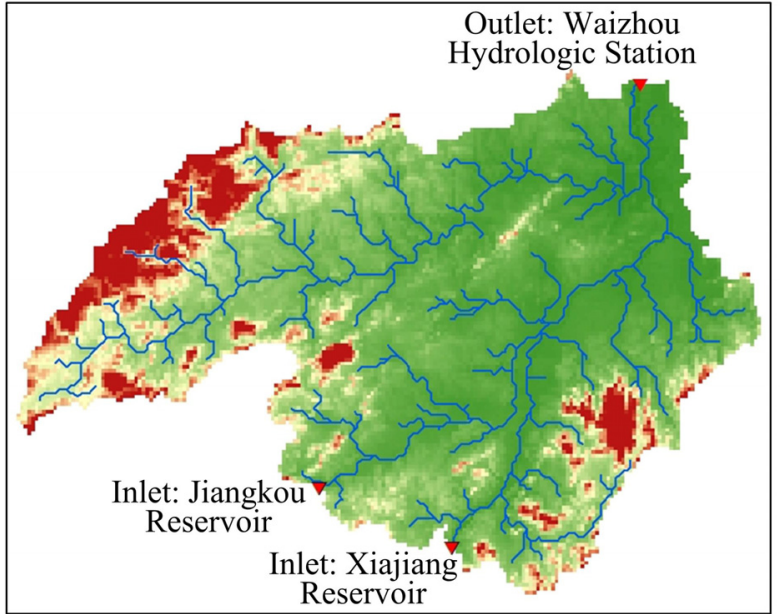

Figure 3. River system at Nanchang section of Ganjiang River

In addition, the hydrological data needed in the model was collected from the Waizhou, Gaoan, Zhangshu and Shanggao stations, and the meteorological data was obtained from the observation data of 76 rainfall stations distributed over the basin. Stations distribution chart is show in the Fig. 4. The weight of each rainfall station is divided by the Tyson Polygon method.

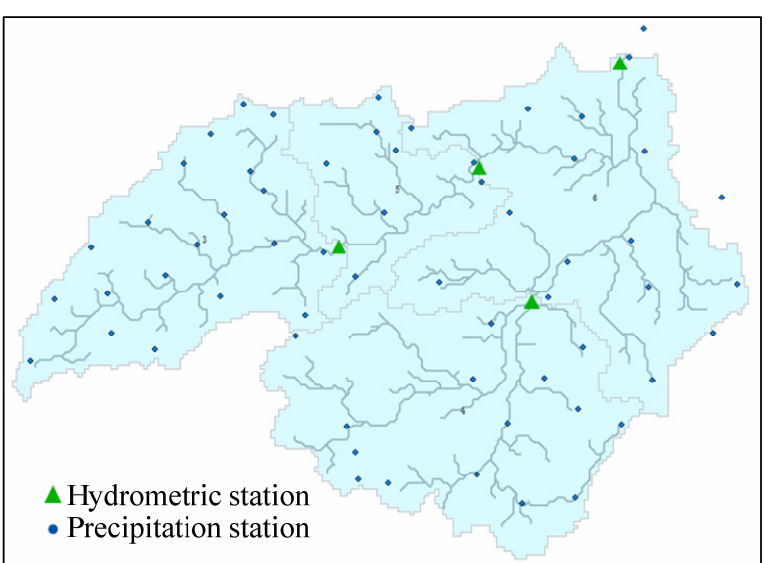

Figure 4. Distribution of hydrometric and rainfall stations

\subsection{Parameter Calibration and Sensitivity Analysis}

The method adopted by EasyDHM model for parameter optimization is to optimize each parameter partition separately, that is, the minimum fitting error between simulated and measured runoff of the control station in each parameter partition is the final objective function. In the study, 23 parameters are selected to calibrate (seen in Table. 1). The lower and higher limit of the optimal space for each parameter can be determined according to the parameter range recommended by the model or manually given based on the physical meaning of the parameter and the characteristics of studied basin.

\begin{tabular}{|c|c|c|c|}
\hline \multicolumn{1}{|c}{ Table 1. Value range of Parameters } \\
\hline \multirow{2}{*}{ Type } & Name & $\begin{array}{c}\text { Lower } \\
\text { limit }\end{array}$ & $\begin{array}{c}\text { Higher } \\
\text { limit }\end{array}$ \\
\hline \multirow{2}{*}{$\begin{array}{c}\text { Overall } \\
\text { parameter }\end{array}$} & ki_sub & 0.5 & 2 \\
\cline { 2 - 4 } & kg_tot & 0.001 & 0.05 \\
\cline { 2 - 4 } & T0 & 0.1 & 0.9 \\
\hline
\end{tabular}




\begin{tabular}{|c|c|c|c|}
\hline Type & Name & $\begin{array}{c}\text { Lower } \\
\text { limit }\end{array}$ & $\begin{array}{c}\text { Higher } \\
\text { limit }\end{array}$ \\
\hline & k_snow & 0.1 & 2 \\
\hline & $\mathrm{k} \_$rain & 0.0001 & 0.001 \\
\hline & $\mathrm{k}$ _run & 0.5 & 3 \\
\hline & p_max & 100 & 500 \\
\hline \multirow{12}{*}{$\begin{array}{c}\text { Runoff yield } \\
\text { parameter }\end{array}$} & $\mathrm{C}$ & 0.1 & 0.3 \\
\hline & IMP & 0 & 0.7 \\
\hline & WM1 & 5 & 100 \\
\hline & WM2 & 50 & 300 \\
\hline & WM3 & 5 & 100 \\
\hline & B & 0.15 & 0.35 \\
\hline & SM & 5 & 100 \\
\hline & EX & 0.5 & 2 \\
\hline & KG & 0.05 & 0.65 \\
\hline & KSS & 0.65 & 0.8 \\
\hline & $\mathrm{KKG}$ & 0.9 & 0.999 \\
\hline & KKSS & 0.05 & 0.95 \\
\hline \multirow{3}{*}{$\begin{array}{c}\text { Flow } \\
\text { concentration } \\
\text { parameter }\end{array}$} & CH_S2 & 0.5 & 1.5 \\
\hline & CH_L2 & 0.5 & 1.5 \\
\hline & CH_N2 & 0.5 & 1.5 \\
\hline
\end{tabular}

In order to obtain the optimal model parameters, LHOAT sampling method is used to analyse the sensitivity of the selected parameters. These parameters are sampled 10 times and combined into 10 sets of parameters by the LH method; and then, OAT sampling is conducted for each set of parameters in the parameter space, due to OAT sampling changes only one parameter in each sampling, thus, 23 evolutions are required in every set of parameters and the total number of sampling is 240 times.

The residual sum of squares between simulated and measured runoff is selected as the objective function of parameter optimization ${ }^{[27]}$, which is shown as follows:

$$
S S Q=\sum_{i=1}^{n}\left(S_{i}-O_{i}\right)^{2}
$$

where, $S_{i}$ is the simulated runoff of the $i$ hydrological station; $O_{i}$ is the measured runoff of the $i$ hydrological station.

In addition, the iterations of the model are constrained by the following two criteria to determine whether each parameter is optimal or not.

1) The objective function cannot improve the accuracy of $0.01 \%$ after five iterations, that is, the value of objective function corresponding to the parameter value reaches to a flat surface of the feasible region, and meanwhile, the iteration can be stopped.

2) After 5 consecutive iterations, the objective function value cannot be significantly changed, and the accuracy of the simulated result is not significantly improved, thus, the objective function is considered in the optimal situation and the iteration can be stopped.

\section{Runoff forecasting verification}

Waizhou station is taken as an example to show the analysis results of the forecasting runoff under different flood situations. The 10 historical flood data from 1998 to 2008 and 5 historical flood data from 2009 to 2015 measured by Waizhou station is used to calibrate and verify the simulated flood processes by the Deterministic Coefficient (DE), respectively. Meanwhile, the flood in different times is predicted and the predicted result is compared with the 47 corresponding measured values from 1998 to 2015 to judge the reliability of the shortterm runoff forecasting model built in the study by the Absolute Error (AE) and Relative Error (RE).

Table. 2 and Table. 3 show that the deterministic coefficient in the flood calibration period is 0.969 ; the simulation accuracy of the flood peak in each flood is high; and the emerged time of flood peak is basically consistent with the actual flood process. The errors of the 47 simulated flood peaks are all less than $20 \%$, and the qualification rate of the simulated flood peaks is $100 \%$; the 45 emerged times of flood peak are less than the allowable error $(6 \mathrm{~h})$, and its qualification rate is $96 \%$; and the calibrated values of the parameters are within the respective value range. Thus, the runoff forecasting schemes are in the Class A, which is better to simulate the large flood, and the small flood can obtain the good forecasting results by some manual adjustment. The short-term runoff forecasting model based on hydrological factors built in the study can be used at Nanchang section of Ganjiang River.

Table 2. Results of flood process calibration and verification

\begin{tabular}{|c|c|c|}
\hline Item & Duration & $\mathrm{DE}$ \\
\hline \multirow{10}{*}{$\begin{array}{l}\text { Calibration } \\
\text { period }\end{array}$} & $1998-05-0108 \sim 1998-09-3008$ & 0.980 \\
\hline & 1999-05-01 08 1999-09-30 08 & 0.941 \\
\hline & $2000-05-0108 \sim 2000-09-3008$ & 0.958 \\
\hline & $2001-05-0108 \sim 2001-09-3008$ & 0.958 \\
\hline & $2002-05-0108 \sim 2002-09-3008$ & 0.968 \\
\hline & 2003-05-01 08 2003-09-30 08 & 0.986 \\
\hline & $2005-05-0108 \sim 2005-09-3008$ & 0.972 \\
\hline & $2006-05-0108 \sim 2006-09-3008$ & 0.955 \\
\hline & $2007-05-0108 \sim 2007-09-3008$ & 0.955 \\
\hline & $2008-05-0108 \sim 2008-09-3008$ & 0.970 \\
\hline \multirow{5}{*}{$\begin{array}{l}\text { Validation } \\
\text { period }\end{array}$} & 2009-05-01 08 2009-09-30 08 & 0.978 \\
\hline & $2010-05-0108 \sim 2010-09-3008$ & 0.982 \\
\hline & $2012-05-0108 \sim 2012-09-3008$ & 0.926 \\
\hline & $2014-05-0108 \sim 2014-09-3008$ & 0.939 \\
\hline & $2015-05-0108 \sim 2015-09-3008$ & 0.937 \\
\hline
\end{tabular}

Table 3. Flood forecasting results (parts of results for example)

\begin{tabular}{|c|c|c|c|c|}
\hline Time & Indicator & $\begin{array}{c}\mathrm{AE} \\
(\mathrm{h})\end{array}$ & $\begin{array}{c}\mathrm{RE} \\
(\%)\end{array}$ & Judgement \\
\hline 1998-05-13 08:00 & Peak flow & 175.2 & $2.74 \%$ & Fit \\
\hline
\end{tabular}




\begin{tabular}{|c|c|c|c|c|}
\hline Time & Indicator & $\begin{array}{l}\mathrm{AE} \\
\text { (h) }\end{array}$ & $\begin{array}{l}\mathrm{RE} \\
(\%)\end{array}$ & Judgement \\
\hline 1998-05-23 08:00 & Emerged time & 3 & & Fit \\
\hline \multirow{2}{*}{$\begin{array}{c}\text { 1999-05-23 08:00 } \\
1999-06-05 \text { 08:00 }\end{array}$} & Peak flow & 196 & $1.96 \%$ & Fit \\
\hline & Emerged time & 4 & & Fit \\
\hline \multirow{2}{*}{$\begin{array}{c}2000-06-2108: 00 \sim \\
2000-07-0408: 00\end{array}$} & Peak flow & 583.8 & $6.62 \%$ & Fit \\
\hline & Emerged time & 1 & & Fit \\
\hline \multirow{2}{*}{$\begin{array}{l}\text { 2001-06-02 08:00 } \\
\text { 2001-07-04 08:00 }\end{array}$} & Peak flow & 396.3 & $3.96 \%$ & Fit \\
\hline & Emerged time & 0 & & Fit \\
\hline \multirow{2}{*}{$\begin{array}{c}2002-06-2508: 00 \sim \\
2002-07-1308: 00\end{array}$} & Peak flow & -30.5 & $0.23 \%$ & Fit \\
\hline & Emerged time & 2 & & Fit \\
\hline \multirow{2}{*}{$\begin{array}{r}2003-06-0608: 00 \sim \\
2003-06-2208: 00\end{array}$} & Peak flow & 105.8 & $2.57 \%$ & Fit \\
\hline & Emerged time & 1 & & Fit \\
\hline \multirow{2}{*}{$\begin{array}{l}\text { 2005-06-15 08:00 } \\
\text { 2005-07-04 08:00 }\end{array}$} & Peak flow & -376.2 & $3.69 \%$ & Fit \\
\hline & Emerged time & 2 & & Fit \\
\hline \multirow{2}{*}{$\begin{array}{l}2006-06-0208: 00 \sim \\
2006-06-24 \text { 08:00 }\end{array}$} & Peak flow & -318.8 & $2.61 \%$ & Fit \\
\hline & Emerged time & 2 & & Fit \\
\hline \multirow{2}{*}{$\begin{array}{l}2009-05-22 \text { 08:00 } \\
\text { 2009-06-13 08:00 }\end{array}$} & Peak flow & 93.7 & $1.37 \%$ & Fit \\
\hline & Emerged time & 0 & & Fit \\
\hline \multirow{2}{*}{$\begin{array}{c}2010-05-0408: 00 \sim \\
2010-06-0308: 00\end{array}$} & Peak flow & 434.5 & $3.29 \%$ & Fit \\
\hline & Emerged time & 2 & & Fit \\
\hline \multirow{2}{*}{$\begin{array}{c}2012-08-0108: 00 \sim \\
2012-08-1608: 00\end{array}$} & Peak flow & 129.2 & $2.43 \%$ & Fit \\
\hline & Emerged time & 4 & & Fit \\
\hline \multirow{2}{*}{$\begin{array}{c}2014-05-12 \text { 08:00 } \\
2014-06-02 \text { 08:00 }\end{array}$} & Peak flow & 125.7 & $1.22 \%$ & Fit \\
\hline & Emerged time & 20 & & UnFit \\
\hline \multirow{2}{*}{$\begin{array}{c}2015-08-0508: 00 \sim \\
2015-08-2708: 00\end{array}$} & Peak flow & -96.6 & $2.71 \%$ & Fit \\
\hline & Emerged time & 0 & & Fit \\
\hline
\end{tabular}

Moreover, the deterministic coefficient in the flood calibration period of the Shanggao, Zhangshu, Gaoan, and station is $0.959,0.976$ and 0.954 , respectively. At Shanggao station, according to the analysis results of 20 flood events from 2009 to 2015, the errors of the 19 simulated flood peaks are all less than $20 \%$, and the qualification rate of the simulated flood peaks is $95 \%$; the 18 emerged times of flood peak are less than the allowable error ( $3 \mathrm{~h}$ ), and its qualification rate is $90 \%$. At Zhangshu station, according to the analysis results of 35 flood events from 1992 to 2015, the errors of the 35 simulated flood peaks are all less than $20 \%$, and the qualification rate of the simulated flood peaks is $100 \%$; the 35 emerged times of flood peak are less than the allowable error $(6 \mathrm{~h})$, and its qualification rate is $100 \%$. At Gaoan station, according to the analysis results of 59 flood events from 1992 to 2015, the errors of the 53 simulated flood peaks are all less than $20 \%$, and the qualification rate of the simulated flood peaks is $90 \%$; the 58 emerged times of flood peak are less than the allowable error $(4.5 \mathrm{~h})$, and its qualification rate is $98 \%$.

\section{Results and discussion}

The short-term runoff forecasting model based on hydrological factors is built in the study to forecast the flood process at Nanchang section of Ganjiang River, and the simulated results are evaluated according the comparison between the forecasting and measured runoff. The simulation accuracy and applicability of the built model are also discussed. The results show that the forecasting results are of high compliance rate and fully meet the accuracy requirement of short-term runoff forecast, which can provide the high-precision boundary conditions for water resources operation model, hydrodynamic and water quality simulation, and also provide the good technical support for the rational allocation of regional water resources. Effects of forecasting uncertainty on reservoirs system for ecological operation deserves further study, and how to operate reservoirs group in big river for ecological protection must be a hot issue in the future.

\section{Acknowledge}

The paper is jointly supported by the Intergovernmental Key International S\&T Innovation Cooperation Program (No.2016YFE0102400), the National Natural Science Foundation of China (Gran No. 51509263), and the Yellow River Engineering Consulting Co., Ltd Postdoctoral Programme (YREC-2018-PD03).

\section{References}

1. Becker A, Serban P. Hydrological models for waterresources system design and operation[J]. Operational Hydrology Report, 1990: 23-35.

2. Montanari A, Brath A. A stochastic approach for assessing the uncertainty of rainfall-runoff simulations[J]. Water Resources Research, 2004, 40(1):75-88.

3. Yao H, Georgakakos A. Assessment of Folsom Lake response to historical and potential future climate scenarios : 2. Reservoir management[J]. Journal of Hydrology, 2001, 249(1):148-175.

4. Georgakakos AP. The value of stream forecasting in reservoir operation $1[\mathrm{~J}]$. Jawra Journal of the American Water Resources Association, 2010, 25(4): 789-800.

5. Sivapragasam C, Vasudevan G, Vincent P. Effect of inflow forecast accuracy and operating time horizon in optimizing irrigation releases[J]. Water Resources Management, 2007, 21(6):933-945.

6. Pianosi F, Ravazzani G. Assessing rainfall-runoff models for the management of Lake Verbano[J]. Hydrological Processes, 2010, 24(22):3195-3205.

7. Komatsu E, Fukushima T, Harasawa H. A modeling approach to forecast the effect of long-term climate change on lake water quality[J]. Ecological Modelling, 2007, 209(2):351-366. 
8. Renjun Z, Yilin Z, Lerun F, et al. The Xinanjiang model[J]. Proc of the Oxford Symposium on Hydrological Forecasting Iahs Publ, 1980, 135(1):371-381.

9. Abebe N A, Ogden F L, Pradhan N R. Sensitivity and uncertainty analysis of the conceptual HBV rainfall-runoff model: implications for parameter estimation.[J]. Journal of Hydrology, 2010, 389(3):301-310.

10. Ferretti R, Paolucci T, Bernardini L, et al. The role of the high resolution weather forecast in estimating the run-offusing a simple hydrological model[J]. Annals of Geophysics, 2003, 46(2):321-329.

11. Chiew F, Vaze J, Viney N, et al. Modelling Runoff and Climate Change Impact on Runoff in 178 Catchments in the Murray-Darling Basin Using Sacramento and SIMHYD Rainfall-runoff Models[J]. Proceedings of Water Down Under, 2008: 2314-2332.

12. Wan Y, Konyha K. A simple hydrologic model for rapid prediction of runoff from ungauged coastal catchments[J]. Journal of Hydrology, 2015, 528(528):571-583.

13. Finnerty B D, Smith M B, Seo D J, et al. SpaceTime Scale Sensitivity of the Sacramento Model to Radar-Gage Precipitation Inputs[J]. Journal of Hydrology, 2015, 203(1):21-38.

14. Chen R S, Pi L C. Diffusive tank model application in rainfall-runoff analysis of upland fields in Taiwan[J]. Agricultural Water Management, 2004, 70(1):39-50.

15. Tsihrintzis V A, Hamid R. Runoff quality prediction from small urban catchments using SWMM[J]. Hydrological Processes, 2015, 12(2):311-329.

16. Wang Z G, Liu C M, Xian-Feng W U. A review of the studies on distributed hydrological model based on DEM[J]. Journal of Natural Resources, 2003, 18(2):168-173.

17. Chen $\mathrm{J}, \mathrm{Wu} \mathrm{Y}$. Advancing representation of hydrologic processes in the Soil and Water Assessment Tool (SWAT) through integration of the TOPographic MODEL (TOPMODEL) features[J]. Journal of Hydrology, 2012, 420(7):319-328.

18. Peters J C, Ely $P$ B. FLOOD-RUNOFF FORECASTING WITH HEC1F1 [J]. Jawra Journal of the American Water Resources Association, 2010, 21(1):7-14.

19. Porrettabrandyk L, Chorman'Ski J, Ignar S, et al. Evaluation and verification of the WetSpa model based on selected rural catchments in Poland.[J]. Journal of Water \& Land Development, 2010, 14((Dec):115-133.

20. Lei $X$ H, Liao W H, Jiang Y Z, et al. Distributed hydrological model EasyDHM I:Theory[J]. Journal of Hydraulic Engineering, 2010, 41(7):786-794.

21. Lei X, Liao W, Wang Y, et al. Development and Application of a Distributed Hydrological Model:
EasyDHM[J]. Journal of Hydrologic Engineering, 2014, 19(1):44-59.

22. Yao C, Li Z J, Bao H J, et al. Application of a Developed Grid-Xinanjiang Model to Chinese Watersheds for Flood Forecasting Purpose[J]. Journal of Hydrologic Engineering, 2009, 14(9):923-934.

23. Gill M A. Flood routing by the Muskingum method[J]. Journal of Hydrology, 1978, 36(3):353363.

24. Karahan H, Gurarslan G, Zong W G. Parameter Estimation of the Nonlinear Muskingum Flood Routing Model Using a Hybrid Harmony Search Algorithm[J]. Journal of Hydrologic Engineering, 2013, 18(3):352-360.

25. Jung $Y$ W, Oh D S, Kim M, et al. Calibration of LEACHN model using LH-OAT sensitivity analysis[J]. Nutrient Cycling in Agroecosystems, 2010, 87(2):261-275.

26. Duan Q, Sorooshian S, Gupta V K. Optimal use of the SCE-UA global optimization method for calibrating watershed models $[\mathrm{J}]$. Journal of Hydrology, 1994, 158(3-4):265-284.

27. Francés F, Vélez J I, Vélez J J. Split-parameter structure for the automatic calibration of distributed hydrological models[J]. Journal of Hydrology, 2012, 332(1):226-240. 